\title{
Development of Axonal Arbors of Layer 4 Spiny Neurons in Cat Striate Cortex
}

\author{
Edward M. Callaway and Lawrence C. Katz \\ Department of Neurobiology, Duke University Medical Center, Durham, North Carolina 27710
}

Spiny neurons in layer 4 of cat striate cortex are the primary recipients of geniculocortical afferents and provide crucial links to other cortical layers for processing visual information. Using intracellular staining, we examined the development of the local axonal projections of these neurons to determine (1) whether the laminar specificity of their projections emerged specifically or was sculpted from transient exuberant projections and (2) whether the emergence of excitatory connections from layer 4 to layer $2 / 3$ could contribute to the activity-dependent development of clustered horizontal connections of layer $2 / 3$ pyramidal neurons.

Differences in the extent of projections to infragranular (layers 5 and 6, which receive sparse projections) versus superficial layers (layers $2 / 3$ and 4 , which receive extensive projections) developed specifically from the outset. By postnatal day 15 (P15) projections to infragranular layers matured and were indistinguishable from those in the oldest animal studied (P33). In contrast, projections to superficial layers continued to increase in complexity after P15. Projections within layer 4 , which were the most elaborate at all ages studied, reached maturity at about $\mathbf{P 2 0}$, while those to layer 2/3 continued to increase in complexity through P33. No evidence for exuberant projections to any of these cortical layers was observed. At very early postnatal ages (P5) projections to the subplate region were evident. These disappeared by P8-P11, suggesting the presence of transient connections from layer 4 spiny neurons to subplate neurons. Binocular deprivation did not prevent the emergence of projections from layer 4 spiny neurons into layer $2 / 3$ or development of normal laminar differences in projection density.

Connections from layer 4 to layer 2/3 emerged after horizontal connections in layer $2 / 3$ were crudely clustered, but in synchrony with the later refinement of clusters. Collaterals from layer 4 cells first crossed into layer 3 at P11, but were extremely short (extending only 50-200 $\mu \mathrm{m}$ beyond the laminar boundary) and uncommon (only 4 of 19 cells). Since by P8 horizontal projections of layer $2 / 3$ pyramidal neurons are already crudely clustered, the emergence of crude clustering is probably independent of layer 4 to layer $2 / 3$ excitatory projections. The proportion of cells projecting to layer $2 / 3$

\footnotetext{
Received July 11, 1991; revised Sept. 19, 1991 ; accepted Sept. 24, 1991.

We thank Drs. G. Einstein and D. Fitzpatrick for comments on the manuscript, Peter Peirce for photographic assistance, and Amy Freeman for help with illustrations. This research was supported by NIH Grants EY06128 (E.M.C.) and EY07960 (L.C.K.). L.C.K. is an L. P. Markey Scholar, and this work was supported in part by a grant from the L. P. Markey Charitable Trust.

Correspondence should be addressed to Edward M. Callaway, Department of Neurobiology, Box 3209, Duke University Medical Center, Durham, NC 27710. Copyright (C) 1992 Society for Neuroscience $0270-6474 / 92 / 120570-13 \$ 05.00 / 0$
}

and the complexity of their arbors both increased in the subsequent weeks, closely matching the timing of both the refinement of crudely clustered horizontal connections and the emergence of visual responsiveness in layer $2 / 3$. These results suggest that projections from layer 4 to layer $2 / 3$ are necessary for activation of layer $2 / 3$ cells by visual stimuli and that this activation may in turn allow layer $2 / 3$ neurons to extract relevant information from the animal's environment to direct the refinement of clustered horizontal connections.

The mammalian visual cortex utilizes a network of highly ordered local connections to synthesize and extract information from incoming visual cues. The local excitatory circuits involved in processing visual information in cat striate cortex have been elucidated by a number of investigators (for review, see Gilbert, 1983; Martin, 1984). We have been investigating the development of these intrinsic connections and how they interact during development in order to understand the mechanisms responsible for assuring the precise connectivity that underlies normal visual perception.

The spiny neurons of layer 4 provide the first and crucial link in cortical visual processing. Layer 4 is the major target of geniculocortical afferents in the cat's striate cortex (LeVay and Gilbert, 1976); although many cell types receive direct connections from these afferents (Davis and Sterling, 1979; Freund et al., 1985), spiny stellates are by far the most abundant type of neuron in layer 4 (O'Leary, 1941; Lund et al., 1979), and they receive large numbers of LGN inputs (Davis and Sterling, 1979; Freund et al., 1985; Einstein et al., 1987). Their receptive fields tend to be simple and monocular, but they are the first in the visual pathway to extract precise orientation information (Hubel and Wiesel, 1962; Kelly and Van Essen, 1973; Gilbert, 1977). They relay this information via extensive excitatory connections within layers 4 and $2 / 3$ and via weaker connections to layers 5 and 6 (Mitzdorf and Singer, 1978; Gilbert and Wiesel, 1979, 1983; Martin and Whitteridge, 1984).

We were interested in whether the adult projection pattern emerges from the lamina-specific outgrowth of axon collaterals or from exuberant growth within all layers followed by a specific reduction of collaterals in infragranular layers. Previous studies in both cats and primates have indicated that at least some interlaminar projections develop specifically from the outset (Lund et al., 1977; Burkhalter et al., 1990; Katz, 1991), and we have proposed that initial, precise laminar specificity is a general characteristic of the development of interlaminar connections (Katz and Callaway, 1991, 1992).

By investigating the timing of the emergence of connections, we addressed two additional developmental questions. First, how does the emergence of connections from layer 4 relate to 
the development of visual excitability in other cortical laminae? The striate cortex of neonatal cats is poorly responsive to visual stimulation (Hubel and Wiesel, 1963); normal levels of excitability gradually emerge during the first several postnatal weeks (Huttenlocher, 1967; Albus and Wolf, 1984). Since geniculocortical afferents are present within layer 4 at birth (Shatz and Luskin, 1986), it is unclear whether the lack of cortical excitation in newborn cats results from a failure to activate these afferents or from a lack of appropriate intrinsic cortical circuitry.

Second, we analyzed the timing of axon collateral growth from layer 4 neurons into layer $2 / 3$ to determine whether activity relayed through this circuit could direct the development of axonal arbors of layer $2 / 3$ neurons. Layer $2 / 3$ pyramidal neurons form clustered intrinsic horizontal axon collaterals that specifically interconnect iso-orientation columns (Gilbert and Wiesel, 1989). During normal development, crude clustering emerges from an initially unclustered distribution and is later refined by the activity-dependent elimination of incorrectly projecting axon collaterals (Callaway and Katz, 1990, 1991). We therefore investigated the possibility that the relevant activity cues could be relayed to layer $2 / 3$ pyramidal neurons via spiny neurons in layer 4 . Finally, axonal arbors of layer 4 spiny neurons from a binocularly deprived cat were studied to determine whether patterned visual activity is necessary for the normal development of this circuitry as it is for the development of horizontal connections (Callaway and Katz, 1991).

\section{Materials and Methods}

Coronal cortical slices were prepared from the striate cortex of a total of eight cats whose ages in postnatal days (P) were P5, P8, P11, P15, $\mathrm{P} 20, \mathrm{P} 26, \mathrm{P} 33$, and $\mathrm{P} 39$. The $\mathrm{P} 39$ cat was deprived of normal patterned visual experience by binocular lid suture prior to natural eye opening (Wiesel and Hubel, 1965). Individual neurons within these slices were intracellularly filled with Lucifer yellow (LY), and the axonal arbors of spiny neurons in layer 4 of area 17 were reconstructed. Between 40 and 80 neurons were filled from each animal. These included cells inadvertently filled outside of layer 4 and neurons with both smooth and spiny dendrites. Only spiny neurons that were in layer 4 and that were judged to be completely filled (see below) were reconstructed and included in further analyses. Somata of reconstructed neurons were located throughout the depth of layer 4 , but the upper part of the layer was sampled more frequently. Because it was not possible to detect the $4 \mathrm{AB} /$ 4C border (see below) and we did not note any difference in the maturation or pattern of projections of neurons in upper versus lower layer 4 , all spiny neurons in the layer were considered together. Axonal arbors were reconstructed from a total of 8 neurons at P5, 6 at P8, 19 at P11, 20 at P15, 9 at P20, 12 at P26, 12 at P33, and 3 from the P39 binocularly deprived cat. The great majority of these cells $(84 \%, 75$ of 89$)$ were spiny stellate neurons (Fig. 1), and the remainder were "star pyramids" (O'Leary, 1941). We found no systematic differences between the local projections of these two populations at any age.

Preparation of cortical slices. Coronal cortical slices were prepared as described previously (Katz, 1987, 1991). Briefly, cats were deeply anesthetized with Nembutal $(60 \mathrm{mg} / \mathrm{kg}$, i.p.), and a large craniotomy was made to expose cortical area 17 . The dura was removed, and area 17 and surrounding tissue were excised by cutting with a scalpel and placed in cold (about $2^{\circ} \mathrm{C}$ ) oxygenated artificial cerebrospinal fluid (composition, in mM: NaCl, $124 ; \mathrm{KCl}, 5 ; \mathrm{KH}_{2} \mathrm{PO}_{4}, 1.25 ; \mathrm{MgSO}_{4}, 2 ; \mathrm{CaCl}_{2}, 3$; $\mathrm{NaHCO}_{3}, 26 ; d$-glucose, 10; kynurenic acid, 2; pH 7.4). The cat was killed by an additional overdose of Nembutal $(60 \mathrm{mg} / \mathrm{kg})$. Slices were prepared and stored for later intracellular dye filling in an oxygenated interface chamber warmed to $34^{\circ} \mathrm{C}$.

Intracellular staining and reconstruction of axonal arbors. Methods for staining and reconstructing axonal arbors have also been described previously (Katz, 1987, 1991). Cortical slices were transferred from the holding chamber to a modified epifluorescence microscope with a recording chamber on a fixed stage heated to $34^{\circ} \mathrm{C}$. Neurons in living in vitro slices were intracellularly impaled with a glass microelectrode filled with $20 \% \mathrm{LY}$ in $0.1 \mathrm{M} \mathrm{LiCl}$. Those cells in which stable electrical re-

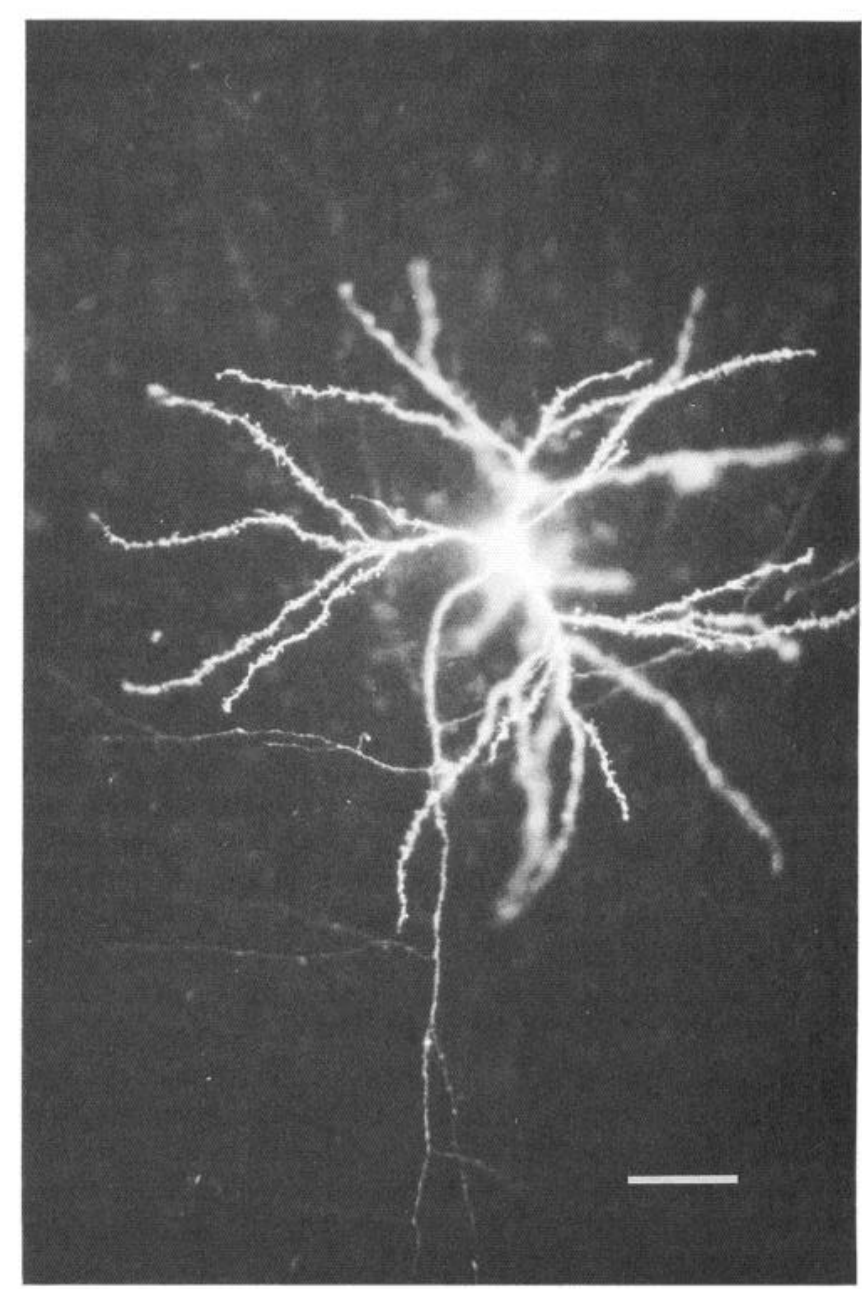

Figure 1. Epifluorescence photomicrograph of an LY-filled spiny stellate neuron in layer 4 of the striate cortex of a P33 cat. The dendritic arbor (thick, spined processes) is that of a typical spiny stellate neuron, with processes of similar length extending in all directions from the cell body to fill a roughly spherical volume. Portions of the axonal arbor are also visible. These are all fine, spine-free processes that are collateral branches of the single, main descending axon that originates at the center of the base of the cell body. Scale bar, $50 \mu \mathrm{m}$.

cordings were maintained were filled with LY by applying negative current pulses $(2.5 \mathrm{~Hz}, 200 \mathrm{msec}$ duration, $0.5-1 \mathrm{nA})$ for $1-10 \mathrm{~min}$. After filling several cells in a slice, it was removed from the chamber and fixed in $10 \%$ formalin in $0.1 \mathrm{~m}$ phosphate buffer for at least $1 \mathrm{~d}$. Slices were then sunk in $30 \%$ sucrose in $0.1 \mathrm{~m}$ phosphate buffer before sectioning with a freezing microtome to a thickness of $50 \mu \mathrm{m}$. Sections were mounted on gelatin-coated slides, dried, cleared in xylene, and coverslipped with Krystalon. Selected neurons were photographed, and all neurons that appeared to be in layer 4 of area 17 and whose axon collaterals could be followed to their ends or until they left the plane of the slice were drawn with a $63 \times$ objective and camera lucida.

After drawings were complete, coverslips were removed by soaking slides in xylene and sections were rehydrated through graded ethanols, stained with nuclear yellow $(0.001 \%$ for 3-6 min), dehydrated, cleared in xylene, and once again coverslipped with Krystalon. Neurons that had been drawn were identified and laminar boundaries were added to the drawings. At this time areal boundaries were also identified. Only neurons with somata in layer 4 of area 17 were analyzed further. Laminar and areal boundaries were determined according to the criteria of Otsuka and Hassler (1962). No attempt was made to differentiate between sublaminae of layer 4 since these borders were not distinct in our nuclear yellow-stained material from young animals. 


\section{P5-P8}

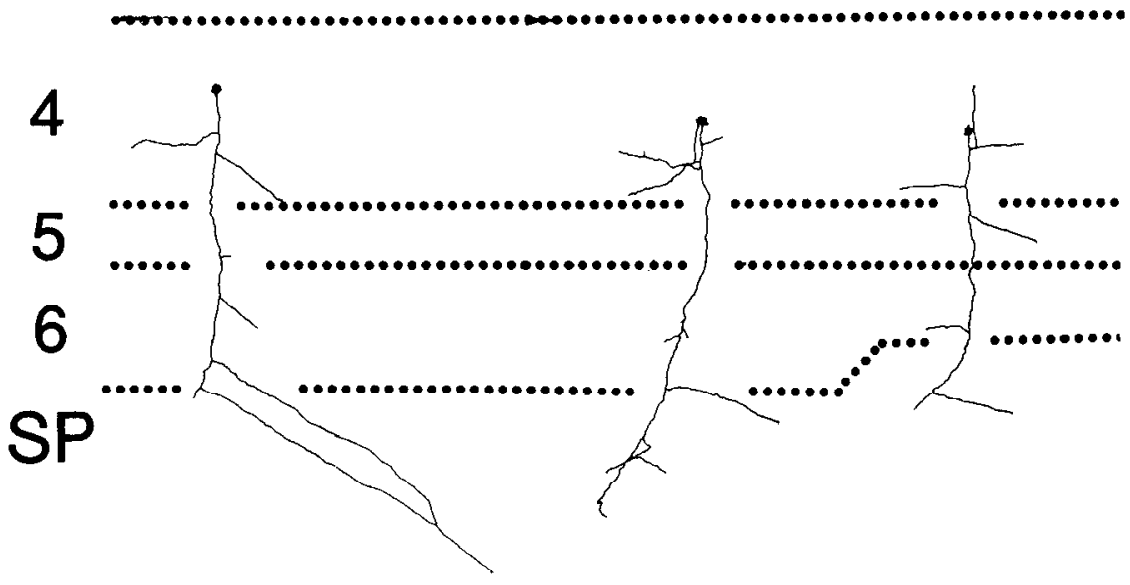

Figure 2. Axonal arbors of spiny neurons from layer 4 of striate cortex of cats aged P5 (top and bottom left) and P8 (bottom right). Cells are viewed in the coronal plane. Cell bodies are indicated by solid polygons, and for clarity their dendritic arbors are omitted. Numbers to the left of the figure indicate cortical layers. At these early ages the main descending axon (originating at the base of the cell body) typically extended into the subplate, and at P5 axons frequently formed collateral branches within the subplate (SP; top). While collateral branches in the cortical plate were generally very short, the longest branches were within layer 4, suggesting that laminar differences in axonal growth were already present. No branches extended into layer $2 / 3$. Scale bar, $200 \mu \mathrm{m}$.

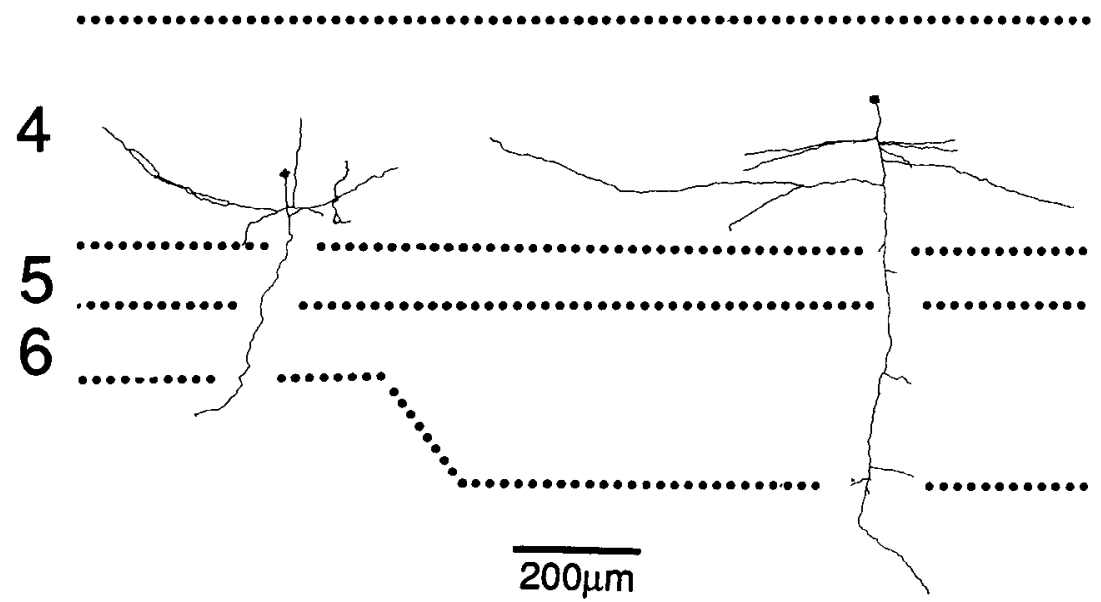

\section{Results}

The results are presented in three sections, each reporting the development of different components of the axonal arbors of layer 4 spiny neurons. Development of axon collaterals within layer 4 and infragranular layers is addressed first, with a particular emphasis on the development of laminar specificity. Development of projections to layer $2 / 3$ is described next, emphasizing the timing with which this circuit emerges relative to the development of clustered connections and the emergence of visual responsiveness in layer $2 / 3$. Finally, axonal arbors of layer 4 spiny neurons from the binocularly deprived cat are described.

Development of projections to deep layers and within layer 4. Axonal arbors from layer 4 spiny neurons at P5 are illustrated in Figure 2 (top, bottom left). At this age the main descending axon, which originated at the base of the cell body, usually extended through the depth of the cortical plate and into the subplate region (six of eight cells). Three cells extended one or more primary collateral branches within the subplate (Fig. 2, top). These branches suggest that layer 4 spiny neurons make connections to cells within the subplate early in their developmental history. In older animals, the main descending axon rarely extended into the subplate (two of six cells at P8) and collateral branches within the subplate were observed for only one other cell in the entire sample of 89 cells (a P15 neuron, not shown). The disappearance of connections to the subplate occurs at the same time that synaptic vesicle-associated antigen staining begins to decrease in the subplate (Chun and Shatz, 1988) and at the early stages of the elimination of subplate neurons, presumably by cell death (Luskin and Shatz, 1985; see Shatz et al., 1988, for review).

We were particularly interested in whether the pronounced quantitative difference in the extent of projections to infragranular (layers 5 and 6) versus more superficial layers ( $2 / 3$ and 4$)$ present in adult layer 4 spiny neurons arises as a result of differential collateral growth or from pruning of transient exuberant projections. Projections to layers 5 and 6 gradually increased in complexity from the earliest age studied until adult levels were reached. Projections to these layers were less extensive than those within layer 4 at all ages studied and reached adult levels earlier than projections within layer 4 or to layer $2 / 3$. We interpret these findings, elaborated below, to indicate that the quantitative laminar differences in projection density result from layer-specific regulation of axon collateral growth.

At P5, collateral branches originated from the main descending axon of layer 4 spiny neurons within layers 5 and/or 6 (Fig. 
Table 1. Extent of axonal arborization in layers $2 / 3$ and 4 at P5P33

\begin{tabular}{|c|c|c|c|}
\hline \multirow[b]{2}{*}{ Age } & \multirow{2}{*}{$\begin{array}{l}\text { Cells projecting } \\
\text { to layer } 2 / 3(\%)\end{array}$} & \multicolumn{2}{|c|}{ Collateral terminations/cell } \\
\hline & & Within layer $2 / 3$ & Within layer 4 \\
\hline P5 & $0(0 / 8)$ & - & $5.0 \pm 0.6(8)$ \\
\hline P8 & $0(0 / 6)$ & - & $10.3 \pm 1.3(4)$ \\
\hline P11 & $21(4 / 19)$ & $1.0 \pm 0$ & $11.7 \pm 0.9(19)$ \\
\hline P15 & $80(16 / 20)$ & $3.6 \pm 0.6(16)$ & $14.1 \pm 1.5(20)$ \\
\hline $\mathrm{P} 20$ & $67(6 / 9)$ & $4.3 \pm 1.3(6)$ & $23.2 \pm 2.1(9)$ \\
\hline $\mathrm{P} 26$ & $67(8 / 12)$ & $6.3 \pm 2.2(8)$ & $27.0 \pm 2.1(12)$ \\
\hline P33 & $83(10 / 12)$ & $11.0 \pm 2.9(10)$ & $19.2+1.7(12)$ \\
\hline
\end{tabular}

Column 1 indicates the percentage of reconstructed layer 4 spiny neurons that had at least one axon collateral extending into layer $2 / 3$. Numbers of projecting cells/total cells are indicated in parentheses. Column 2 indicates the mean $( \pm$ SEM) number of axon collateral branches per cell terminating in layer $2 / 3$. The numbers of cells are indicated in parentheses. Only those cells that had at least one collateral within layer $2 / 3$ were included in this calculation. Column 3 indicates the mean $( \pm$ SEM) number of axon collateral branches per cell that terminated in layer 4 . The numbers of cells are indicated in parentheses. Laminar boundaries for two of the P8 neurons could not be established due to the loss of sections during counterstaining, and these neurons were therefore not included in quantitative analyses.

2, top), although some cells lacked such collaterals (Fig. 2, bottom left). When present, these branches were typically less than $100 \mu \mathrm{m}$ in length but sometimes extended up to $150 \mu \mathrm{m}$. The most extensive and complex collateral branches at P5 were within layer 4 . These extended horizontally, up to $300 \mu \mathrm{m}$ from the cell body and often had secondary collateral branches.

Between P5 and P8 the pattern of projections to layers 5 and 6 did not change noticeably. However, within layer 4 , the axonal arbors increased in both length and complexity. The average number of collateral branches terminating in layer 4 per cell more than doubled (significant at $p<0.01$, Student's $t$ test; Table 1, Fig. 3B).

Between P8 and P11 projections to infragranular layers again changed little while axonal arbors within layer 4 continued to increase in complexity. Typical P11 cells (Fig. 4, top) resembled the most complex P8 cell. The most elaborate branching remained confined to layer 4 , and a few cells formed tertiary axonal branches within this layer that were not observed at P5 or P8 (Fig. 4, bottom). These infrequent branches contributed to a modest increase in the number of collateral terminations in layer 4 per cell (Table 1, Fig. $3 B$ ). Primary collateral branches from the main descending axon within infragranular layers remained sparse and unbranched but were somewhat longer (up to about $200 \mu \mathrm{m}$ ) than those observed at P5-P8.

Figure 5 illustrates the axonal arbors of 4 of the 20 layer 4 spiny neurons reconstructed from the P15 animal. Between P11 and P15 modest increases in the complexity of axonal arbors in layers 4-6 resulted in adultlike projections in layers 5 and 6. The most noticeable change in the projection to infragranular layers was the presence of secondary axonal branches that originated in layer 4 and extended downward through the depth of layer 5 (Fig 5, top left). This type of collateral was observed for 7 of 20 cells at P15 but for none of the cells from younger animals. Two other P15 cells had tertiary branches in layer 6 emerging from secondary collaterals that originated in layer 6 (not shown).

Between P11 and P15 horizontal axon collaterals within layer 4 changed most in length rather than in degree of branching. The longest collaterals extended up to $800 \mu \mathrm{m}$ from the cell
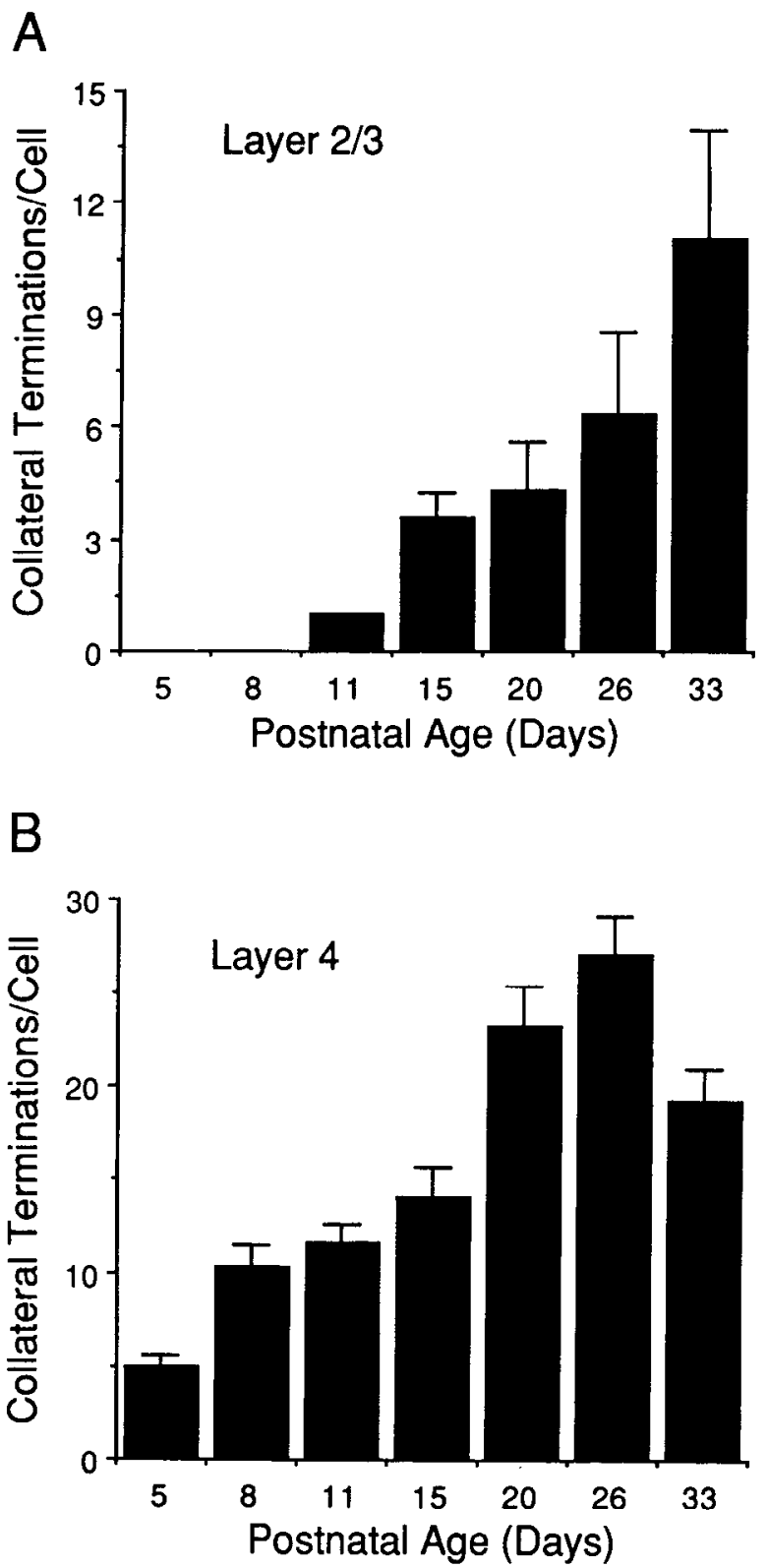

Figure 3. Histograms illustrating the mean $( \pm$ SEM) numbers of axon collateral branches terminating within layer $2 / 3(A)$ or layer $4(B)$ per cell for layer 4 spiny neurons from animals of various postnatal ages. In $A$, only neurons making a projection to layer $2 / 3$ are considered. $A$, The average number of axon collateral branches terminating within layer 2/3 per cell increased stcadily from P11, when the first such branches were observed, until P33. $B$, The complexity of axonal arbors within layer 4 also increased steadily with age. Differences between the values at $\mathrm{P} 20$ vs. $\mathrm{P} 26$ and $\mathrm{P} 20$ vs. P33 were not statistically significant $(p>$ 0.05 ), suggesting that these arbors were mature at about P20. Branching in layer 4 was considerably more complex than in layer $2 / 3$ at all ages; by P8-P11 the average number of collateral terminations per cell was already as high within layer 4 as it would be within layer $2 / 33$ weeks later.

body (not shown), versus $600 \mu \mathrm{m}$ at P8-P11, and horizontal collaterals longer than $500 \mu \mathrm{m}$ were observed for a fivefold higher proportion of cells (18 of 20 at P15 vs. 2 of 25 at P8P11). The number of collaterals terminating in layer 4 per cell increased by only about $20 \%$ (not significant, $p>0.05$; Table 1, Fig. 3B).

Figure 6 illustrates axonal arbors of spiny stellate neurons 

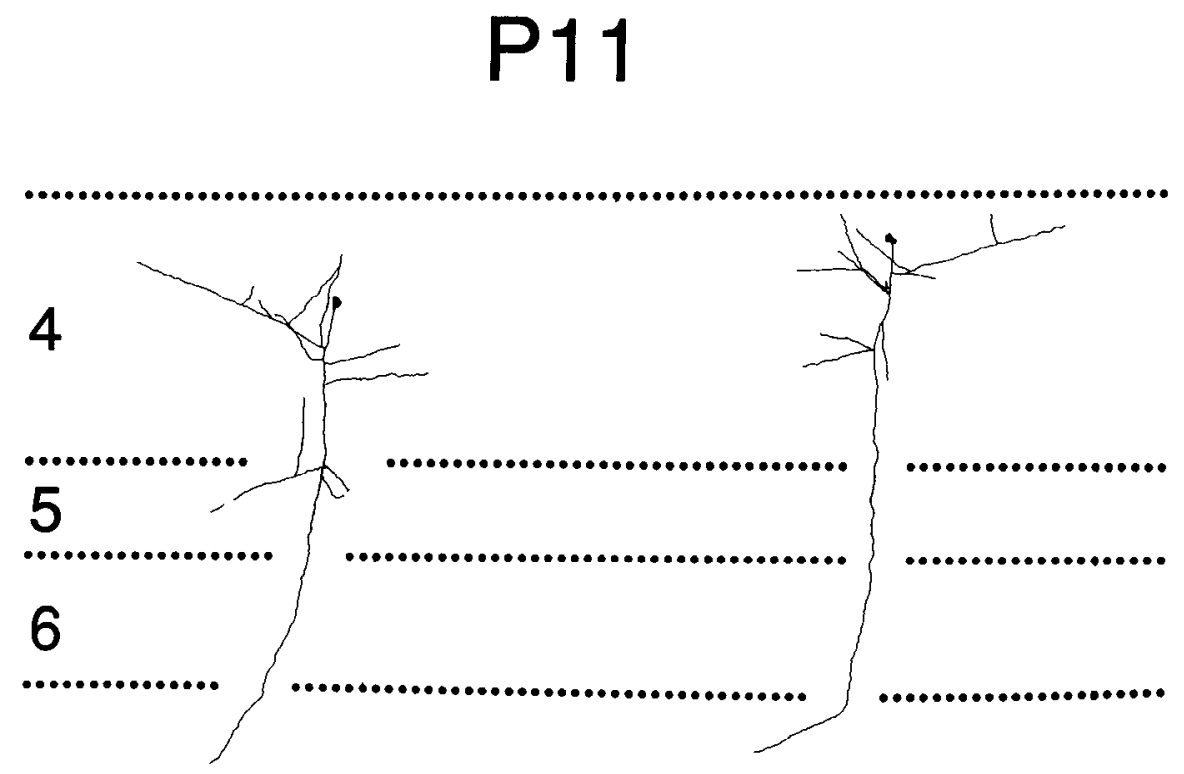

Figure 4. Axonal arbors of spiny neurons in layer 4 at P11. Conventions are as in Figure 2. Collateral branches within layer 4 at this age were already considerably more extensive than those in infragranular layers. Very few cells had collaterals extending to layer 3 ; when present, these branches were very short (bottom left). Axonal branches were absent from the subplate. Scale bar, 200 $\mu \mathrm{m}$.

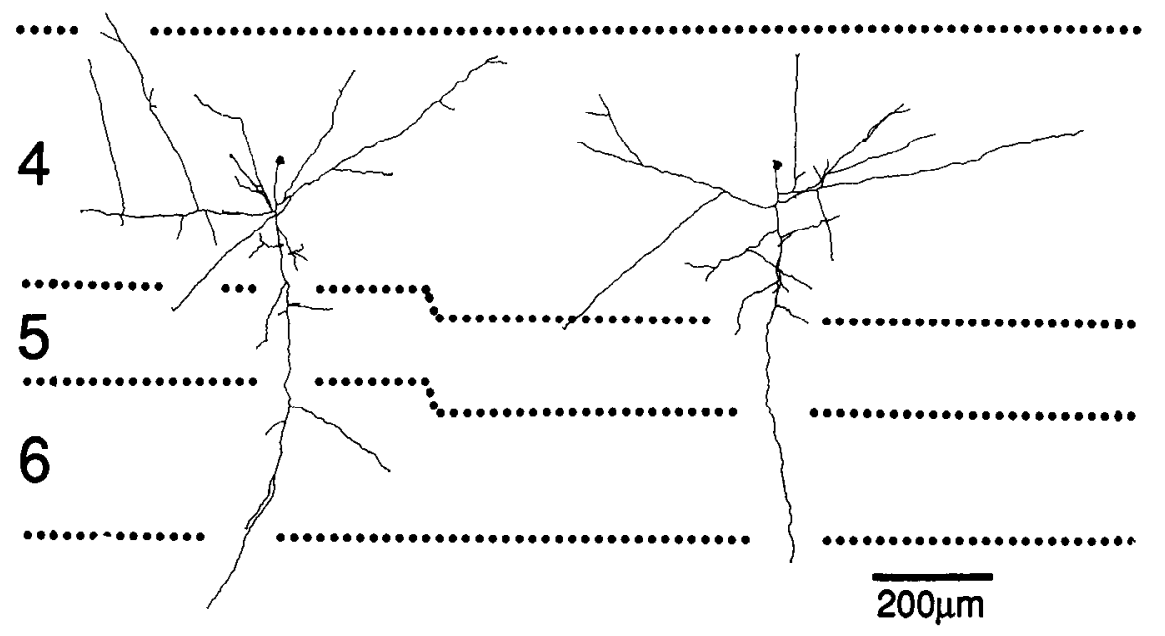

from the $\mathrm{P} 20$ animal. After $\mathrm{P} 15$ the patterns of projections from layer 4 spiny neurons to layers 5 and 6 changed little. Projections within layer 4 , however, continued to mature. While the length of horizontal collaterals within layer 4 remained similar between P15 and P20, their complexity increased considerably (compare Figs. 5, 6). The average number of collateral terminations per cell rose significantly by $65 \%(p<0.001$; Table 1 , Fig. $3 B)$. By $\mathrm{P} 20$, the layer 4 arborization reached its mature extent as no significant differences between the average number of collateral terminations per cell were observed at P20 and P26 or P33 (Table 1, Fig. 3B).

In sum, projections to infragranular layers were always less extensive than those to layer $\mathbf{4}$ and reached maturity earlier (by P15 vs. P20). We detected no evidence of exuberant projections to infragranular layers at any age studied.

Timing of the development of projections from layer 4 to layer 2/3: relationship to the development of clustered horizontal connections. In the adult cat, layer $2 / 3$ pyramidal neurons receive strong excitatory projections from spiny neurons in layer 4
(Mitzdorf and Singer, 1978; Gilbert and Wiesel, 1979, 1983; Martin and Whitteridge, 1984). These layer $2 / 3$ cells have long, clustered horizontal axon collaterals whose development relies on patterned visual activity to achieve a normal adult pattern of connectivity (Callaway and Katz, 1991). Thus, excitatory projections from layer 4 to layer $2 / 3$ could play an important role in the development of these horizontal axon collaterals.

Although P5-P8 cells already had horizontal axon collaterals within layer 4 long enough to reach layer 3 easily had they been vertically oriented, no axon collaterals crossed the layer $3 / 4$ border (see Fig. 2). Not until P11 did axons from layer 4 spiny neurons first cross into layer 3 ; these projections were minimal (Fig. 4, bottom left). Of 19 cells, only 4 projected to layer 3 (Table 1, Fig. 7) with a single, short collateral extending less than $200 \mu \mathrm{m}$ into the layer. Even before this time (by P8), horizontal connections of layer $2 / 3$ pyramidal cells are crudely clustered (Callaway and Katz, 1990). Thus, projections from spiny neurons in layer 4 up to layer $2 / 3$ are not necessary for the initial emergence of crude clusters. Although this pathway 


\section{P15}
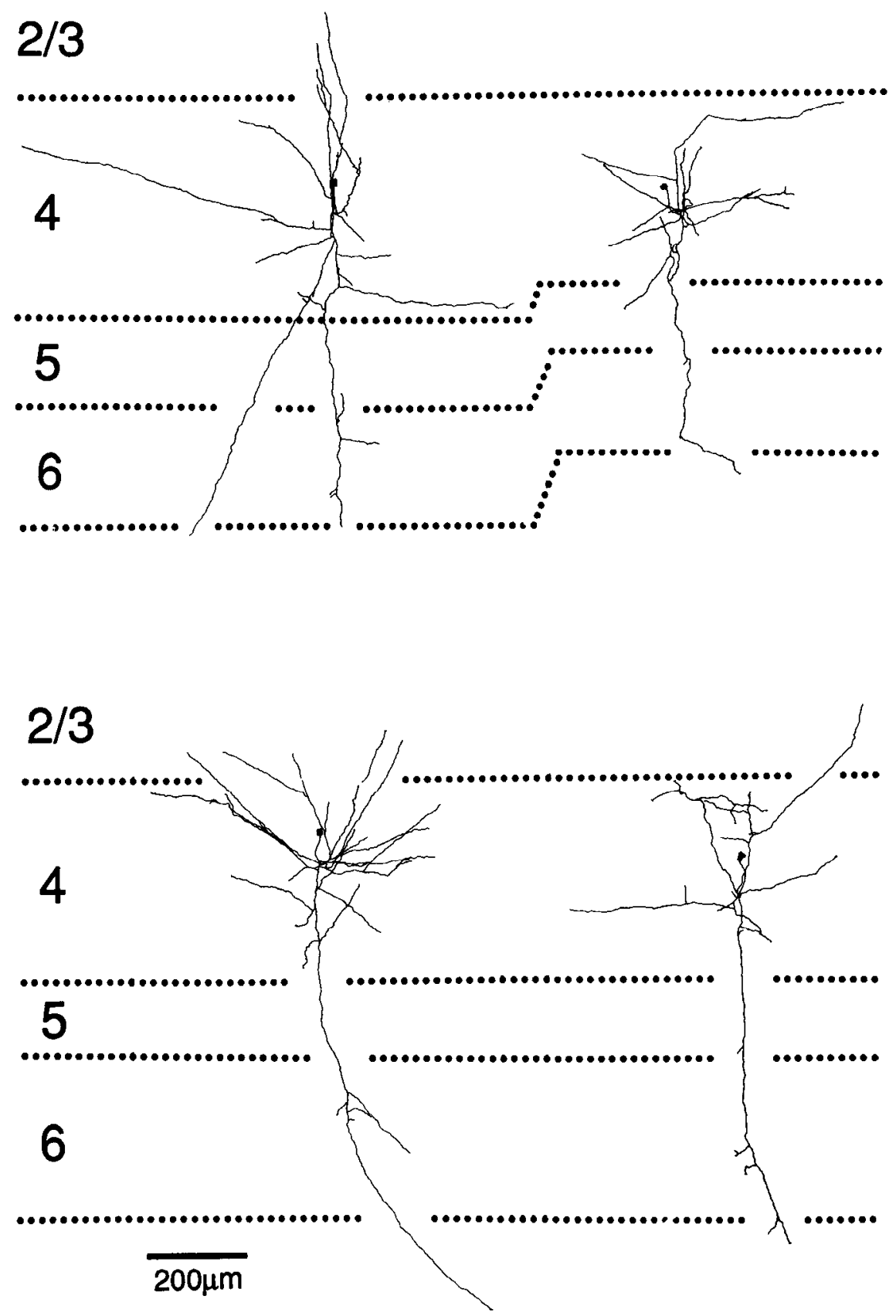

Figure 5. Axonal arbors of spiny neurons in layer 4 at $P 15$. Conventions are as in Figure 2. Collateral branching in superficial layers $(2 / 3$ and 4$)$ continued to be considerably more extensive than in infragranular layers. Branches extending into layer $2 / 3$ were much more common than at P11, but still sparse. Collateral branches descending from layer 4 into infragranular layers were first seen at this age (top left). Scale bar, $200 \mu \mathrm{m}$. provides the major excitatory input to layer $2 / 3$ in adult animals, these findings do not exclude the possibility that the initial emergence of crude clusters requires activity cues that could reach layer $2 / 3$ via other pathways (see Discussion).

Between P11 and P15 the extent of projections from layer 4 spiny neurons to layer $2 / 3$ increased considerably. By P15 (Fig. 5 ), the proportion of layer 4 spiny neurons with axons projecting to layer $2 / 3$ reached adult levels; $80 \%$ (16 of 20 ) had layer 4 to $2 / 3$ projections (Table 1 , Fig. 7 ). For cells projecting to layer $2 /$ 3 , this projection was at least twice as extensive as even the most extensive projection at P11. These cells typically had multiple branches penetrating the layer $3 / 4$ border (Fig. 5, left) significantly increasing the average number of collateral terminations in layer $2 / 3$ per cell (excluding cells not projecting to layer $2 / 3$; $p<0.025$; Table 1, Fig. 3A). The extent and complexity of branching within layer $2 / 3$, however, were still far from mature.

At P20 (axonal arbors illustrated in Fig. 6), two-thirds (6 of 9) of layer 4 spiny neurons had projections to layer $2 / 3$ (Table 1, Fig. 7), similar to the value already reached by P15. While the projection was typically more extensive at P20 than at P15, it still had not reached adult levels; the number of collateral branch terminations in layer $2 / 3$ increased only slightly (Table 1, Fig. 3A). 


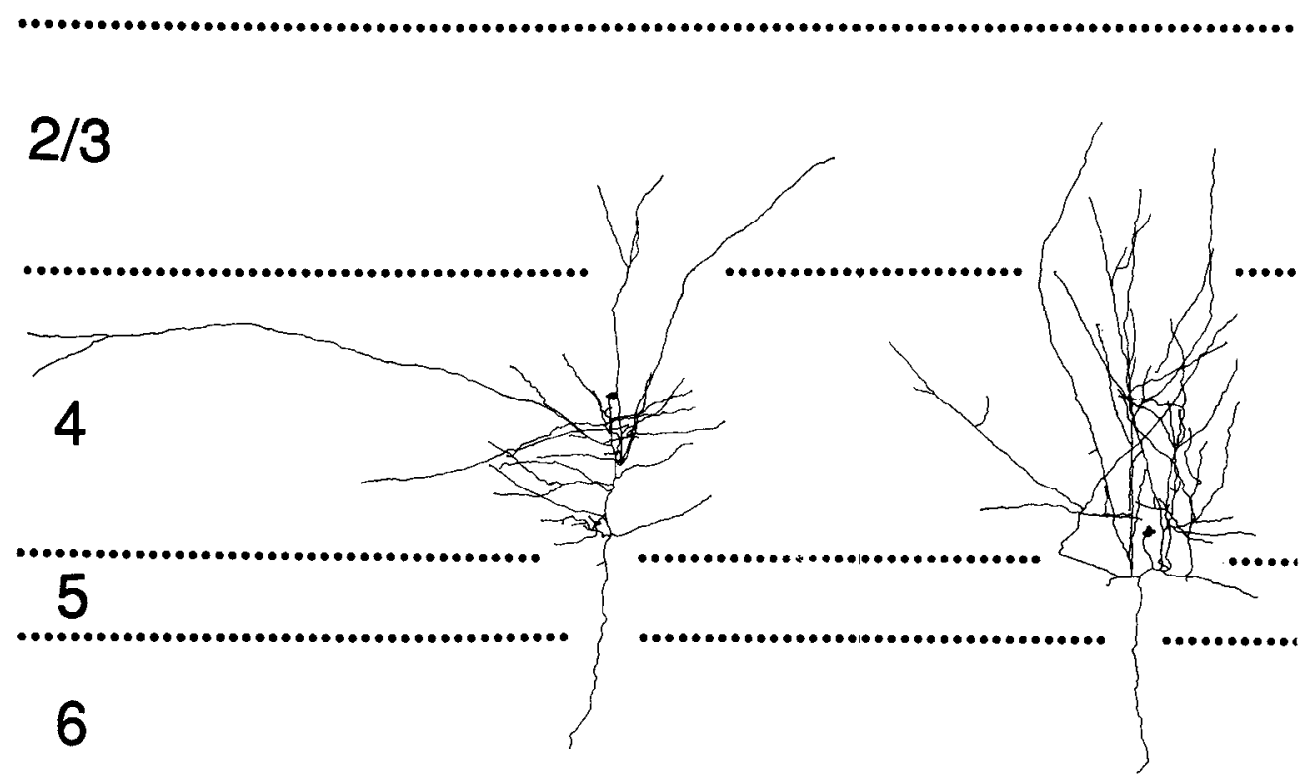

Figure 6. Axonal arbors of spiny neurons in layer 4 at $P 20$. Conventions are as in Figure 2. Projections to infragranular layers remained sparse at this age, while there was a substantial increase in branching within layer 4 and a modest increase in layer $2 / 3$ relative to $P 15$ values. Scale bar, $200 \mu \mathrm{m}$.

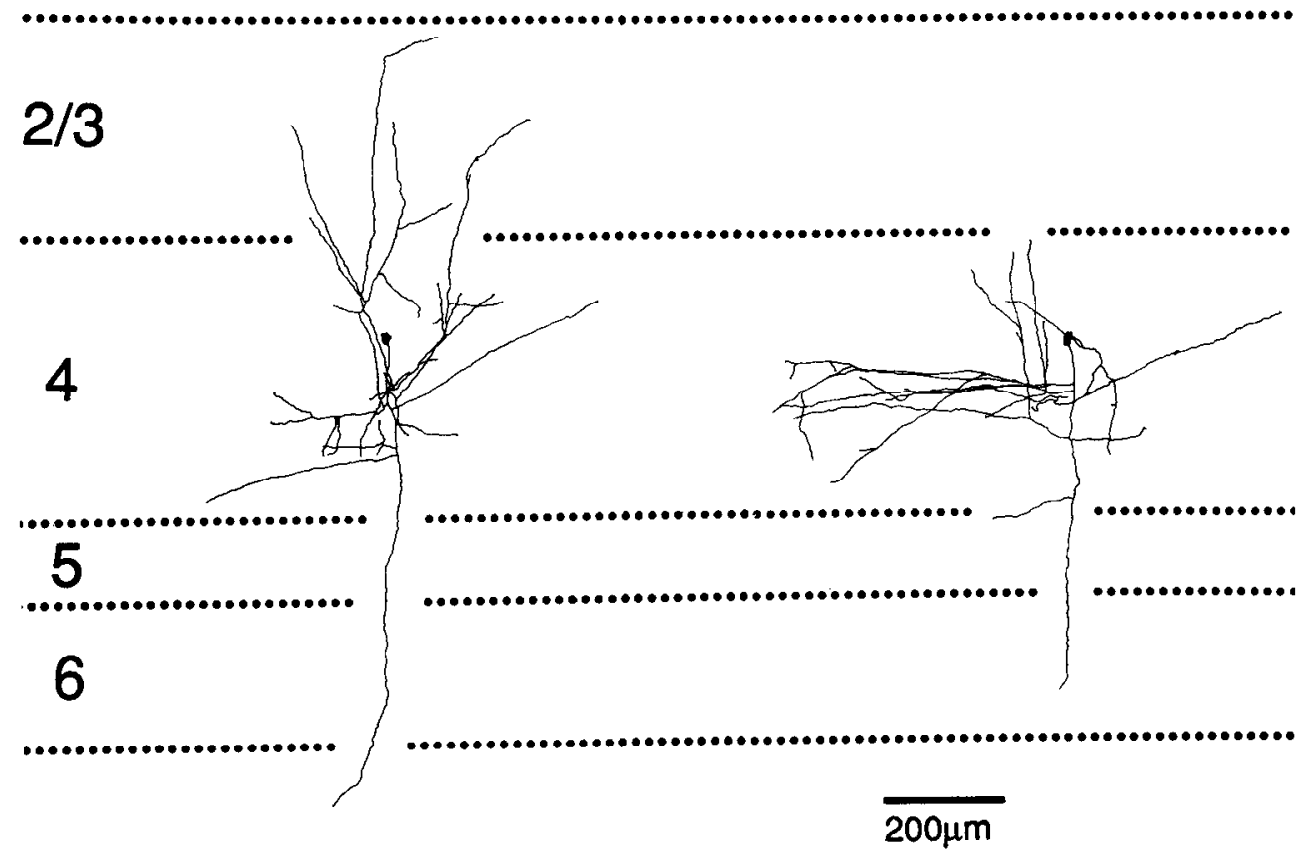

After P20 the extent of the layer 4 to layer $2 / 3$ projection continued to increase dramatically [Figs. 8 (P26), 9 (P33)], but there was no deviation from the already established adultlike percentage of cells projecting to layer $2 / 3$. Two-thirds of the reconstructed cells ( 8 of 12 ) projected to layer $2 / 3$ at P26, and more than $80 \%$ (10 of 12) at P33 (Table 1, Fig. 7). The average numbers of collateral terminations per cell increased by $47 \%$ between P20 and P26 and by an additional 75\% between P26 and P33 (Table 1, Fig. 3A).

Excitatory projections from layer 4 to layer $2 / 3$ therefore grad- ually elaborate from P11, when the first very sparse projections invade layer $2 / 3$, until an adultlike state is established at P33. This interval closely corresponds to the timing of the emergence of visual excitability outside of layer 4 and to the refinement of clustered horizontal connections (see Discussion). The above findings are summarized in Figure 10.

Influence of binocular deprivation. Binocular lid suture prevents the refinement of clustered horizontal connections of layer $2 / 3$ pyramidal neurons (Callaway and Katz, 1991). As described above, there is also a close correlation between the timing of 


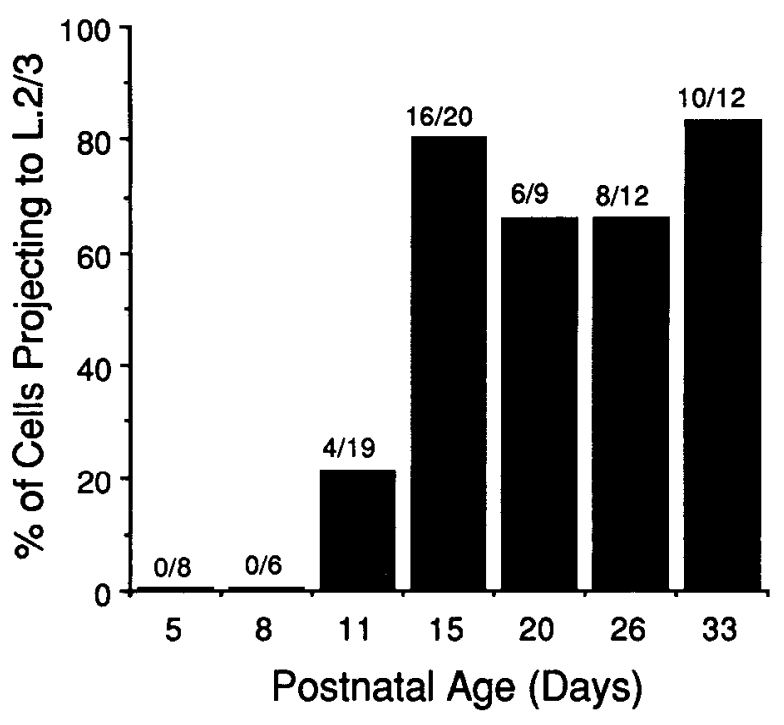

Figure 7. Percentages of spiny neurons in layer 4 with axon collaterals in layer $2 / 3$ at different postnatal ages. The first cells with branches to layer $2 / 3$ were observed at $P 11$; the percentage of projecting cells reached adult levels by P15.

cluster refinement and the elaboration of projections from layer 4 spiny neurons to layer $2 / 3$. Thus, the lack of cluster refinement in layer $2 / 3$ of lid-sutured animals could result from abnormal connections from layer 4 . For example, layer 4 spiny neurons might not project to layer $2 / 3$ at all, thus failing to relay necessary activity cues to that layer. Alternatively, projections to layer $2 / 3$ might be more widespread than normal such that the infor- mation reaching the pyramidal neurons would be too crude to allow normal cluster refinement.

To investigate whether patterned visual experience was necessary for the emergence of the layer 4 to $2 / 3$ connection, neurons from a P39 cat, binocularly deprived by lid suturing prior to natural eye opening, were filled with LY (illustrated in Fig. 11). While the small sample size (three well-filled cells) precludes quantitative analyses, these cells appeared similar in all respects to normal adult or P33 cells (Fig. 11). Extensive axonal arborizations were present in layers $2-4$, while projections to infragranular layers were sparse, as in normal animals. None of the projections appeared more or less extensive than normal. Thus, patterned visual activity is not necessary for the emergence of projections from layer 4 to layer $2 / 3$ or for the development of the laminar specificity of axonal arbors of layer 4 spiny neurons. Analysis of this single time point cannot, of course, rule out the possibilities that (1) binocular deprivation could alter the timing of the development of axonal arbors of layer 4 spiny neurons or (2) that early exuberance of projections from layer 4 is eliminated before P39.

\section{Discussion}

Ironically, methodological limitations made intrinsic cortical circuitry of developing animals among the first to be described but the last to be well understood. The Golgi method allowed limited reconstructions of cortical neurons in both young and adult animals, but the brains of developing animals provided the best axonal reconstructions (Ramon y Cajal, 1911; Lund et al., 1977). More recently, the use of intracellular staining techniques to visualize neurons in the visual cortex of intact cats allowed axonal arbors to be reconstructed more completely,

\section{P26}

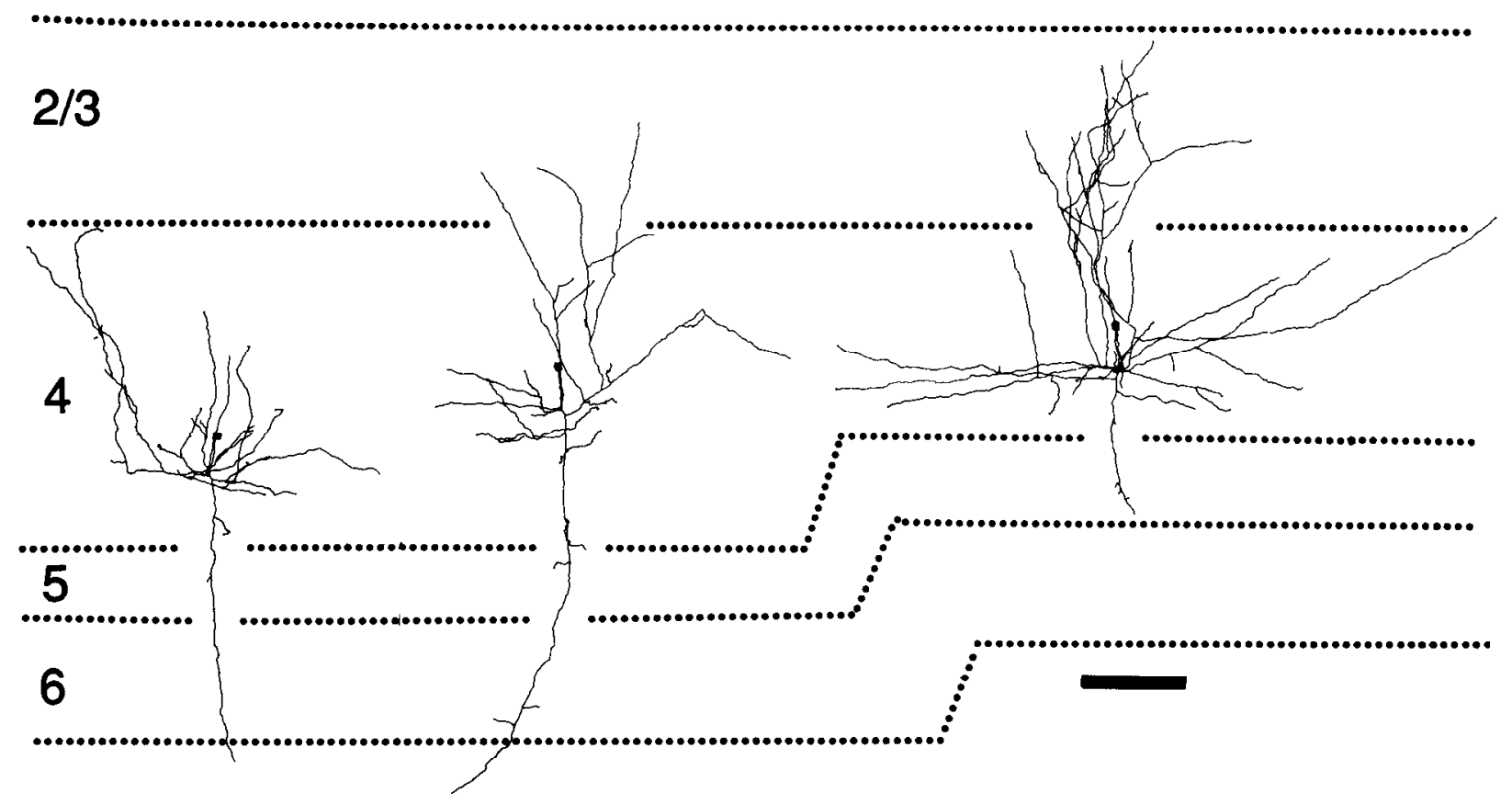

Figure 8. Axonal arbors of spiny neurons in layer 4 at P26. Conventions are as in Figure 2. Axonal arbors within layer $2 / 3$ continued to increase in complexity between P20 and P26 with some displaying adultlike complexity (right). Projections to infragranular layers remained sparse and axonal arbors within layer 4 were similar to those observed at P20. Scale bar, $200 \mu \mathrm{m}$. 


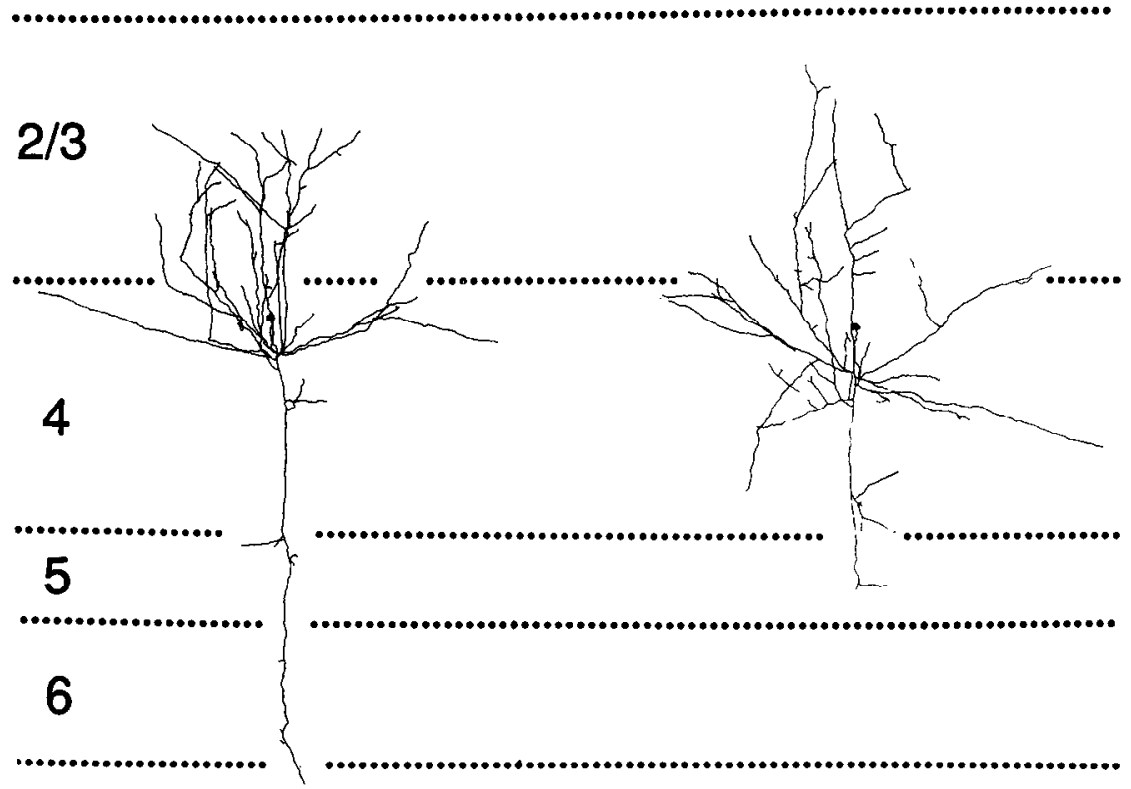

Figure 9. Axonal arbors of spiny neurons in layer 4 at P33. Conventions are as in Figure 2. Axonal branching in layer $2 / 3$ increased to an adultlike level of complexity, while the levels previously established in other layers were maintained. Scale bar, $200 \mu \mathrm{m}$.

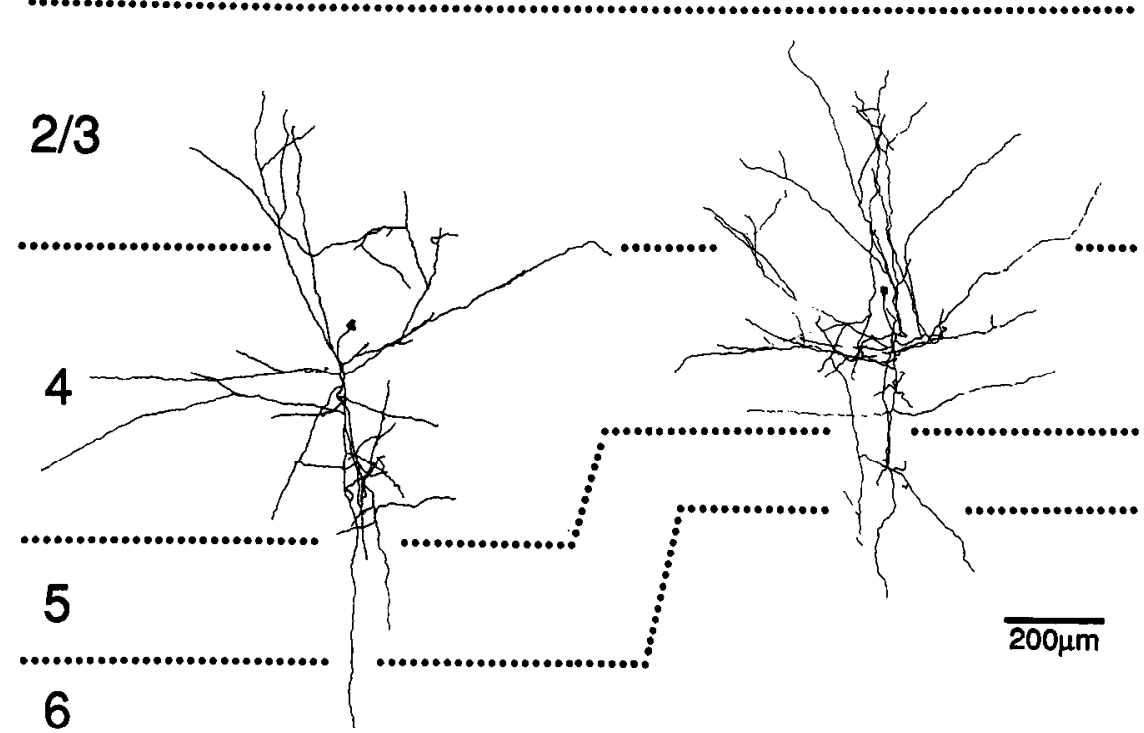

revealing considerably more detail about the intrinsic connectivity of the striate cortex (for review, see Gilbert, 1983; Martin, 1984). These experiments are very difficult in adult animals, and the smaller size of neurons in developing animals makes this approach impractical. The use of intracellular staining in brain slices, however, allows visualization of extensive axonal arbors even in very young animals. Here, we use this technique to address the development of projections from layer 4 spiny neurons, as they provide a crucial link in the cortical processing of visual information.

Development of laminar specificity. The results presented here support the hypothesis that the initial outgrowth of specific ver- tical connections is regulated in a layer-specific manner without the involvement of transient exuberant projections, as first proposed by Lund et al. (1977). The lamina-specific growth of axon collaterals has been clearly documented in the development of layer 2/3 pyramidal neurons (Burkhalter et al., 1990; Katz, 1991). These cells project within layer $2 / 3$ and to infragranular layers, while projections within layer 4 are extremely rare. In both cats and humans the development of vertical intrinsic projections of layer $2 / 3$ pyramidal neurons is specific from the earliest times that collateral sprouts form.

In the adult cat, projections from layer 4 spiny neurons to layer $2 / 3$ and within layer 4 are extensive, while those to infra- 

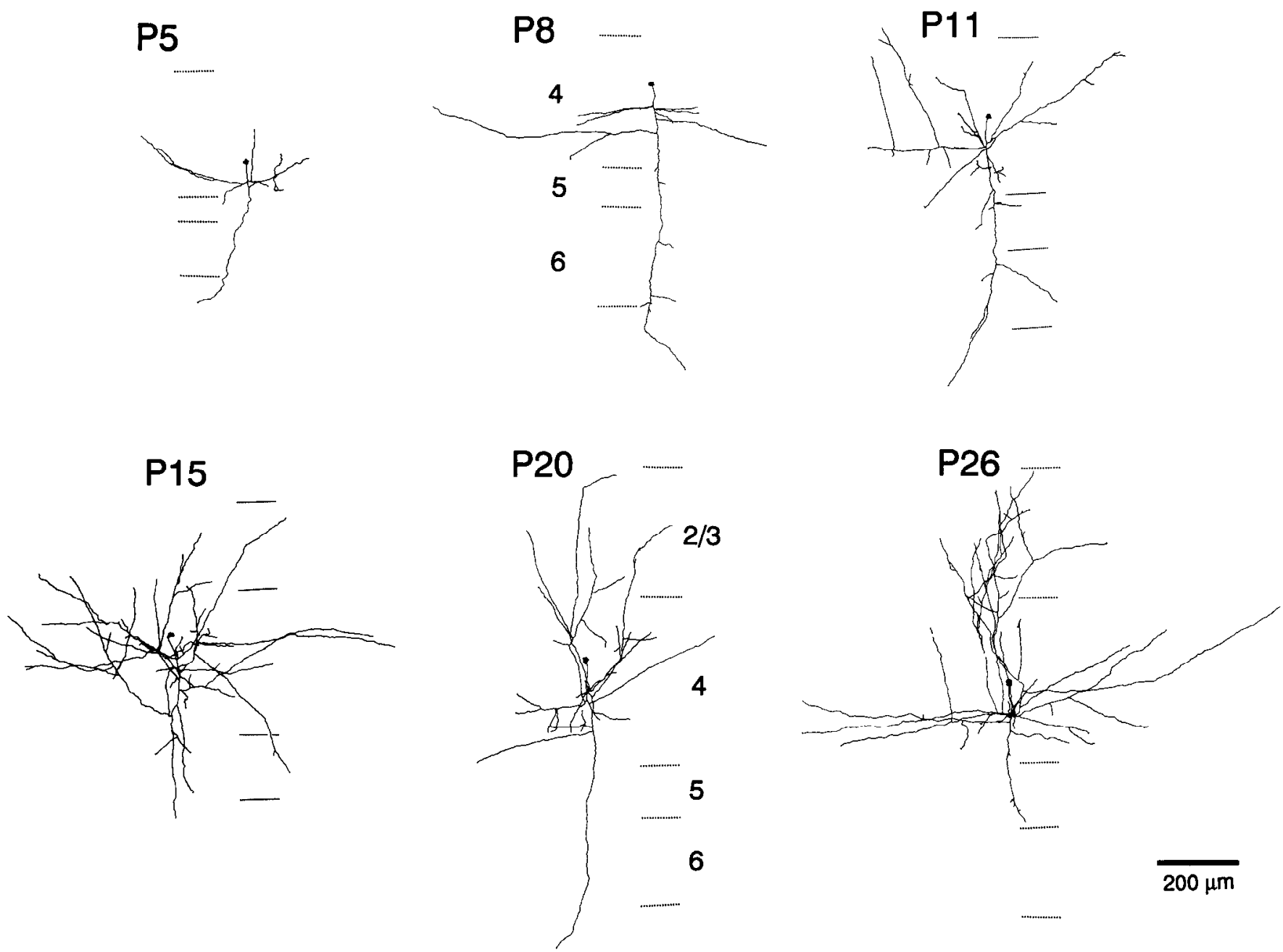

Figure 10. Summary figure illustrating representative axonal arbors of spiny neurons in layer 4 of cats aged P5-P26. Conventions are as in Figure 2. Projections to infragranular layers were sparse at all ages studied; exuberant projections to these layers were never observed. The laminar differences in axonal branching between upper and lower layers were maintained throughout the entire developmental period studied, becoming more pronounced as the projections to more superficial layers ( $2 / 3$ and 4$)$ grew. Projections to layer $2 / 3$ first emerged at P11, which is after intrinsic horizontal axons of layer $2 / 3$ pyramidal neurons form crude clusters. After P11, projections to layer $2 / 3$ became progressively more extensive, reaching adultlike proportions by $\mathbf{P 3 3}$. The timing with which these projections were elaborated closely parallels the refinement of clustered intrinsic connections of layer $2 / 3$ pyramidal neurons and the emergence of visual responsiveness in layer $2 / 3$. Scale bar, $200 \mu \mathrm{m}$.

granular layers are sparse (Gilbert and Wiesel, 1979, 1983; Martin and Whitteridge, 1984). We found that this difference arises from differential growth and branching of axon collaterals in supcrficial versus decp layers, rather than by an equal rate of growth followed by a reduction of projections to the deep layers. Because we did not follow individual neurons during their course of maturation, it is possible that some neurons may undergo minor reductions in their initial extent of axon branching. Nonetheless, the extent of growth is clearly regulated differently in different layers.

The development of axonal arborizations of layer 4 spiny stellate neurons in the macaque monkey has been described by Lund et al. (1977). As in the cat, layer 4 spiny neurons in the macaque project sparsely to infragranular layers and more extensively to superficial layers. The pattern of lamination of layer 4 is more complex, however, than in the cat. Lund et al. (1977) report that specific types of layer-specific projections are already present for some layer 4 spiny stellates at the earliest age studied (embryonic day 127) and do not report extensive projections to deep laminae at any age. This study, however, begins at a later stage of cortical maturation than the present study.

In the course of our study we noted a possible exception to the rule of initial laminar specificity. Axonal branching was observed in the subplate region at P5 but not at later ages, suggesting the presence of early transient connections to subplate neurons. Despite our evidence that vertical projections are specific from the outset, it is not surprising that subplate connections would be eliminated. The subplate does not persist in the adult cat, but disappears, presumably as the result of naturally occurring cell death (Luskin and Shatz, 1985; Shatz et al., 1988). Thus, any connections from layer 4 to the subplate are not necessarily "incorrect." Instead, they may play an important role in the early activity-dependent development of cortical connectivity, as suggested by Shatz and her colleagues, who have implicated subplate neurons in early cortical circuits (Friauf et al., 1990).

Activity dependence of laminar specificity. In contrast to the early specificity of intrinsic vertical connections, clustered in- 


\section{P39 BD}

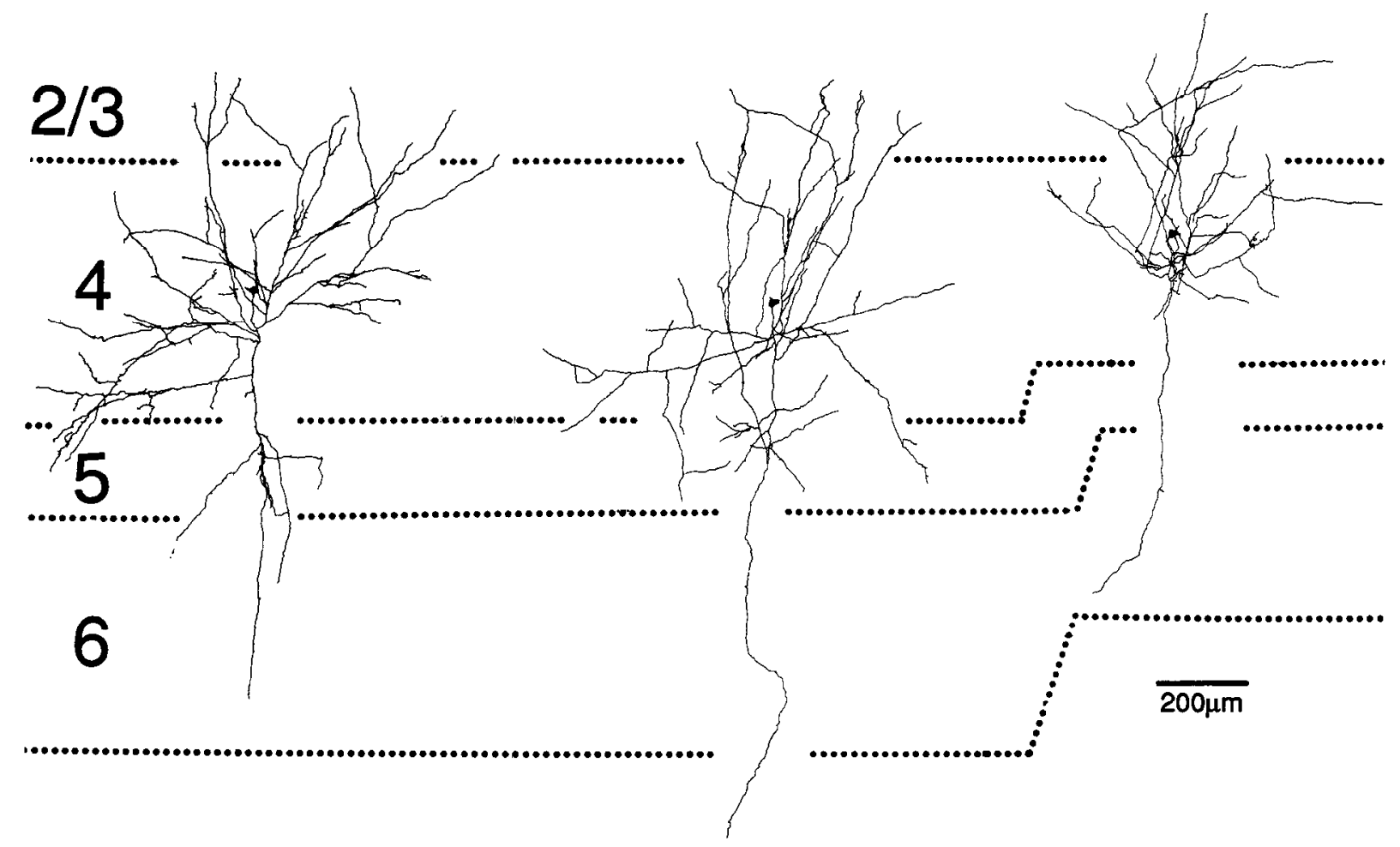

Figure 11. Axonal arbors of spiny neurons in layer 4 of a P39 binocularly deprived cat. Conventions are as in Figure 2. Like normal adult layer 4 spiny neurons, these cells made extensive projections to layer $2 / 3$ and within layer 4 and projected only weakly to infragranular layers. Scale bar, $200 \mu \mathrm{m}$.

trinsic horizontal collaterals in the cat develop exuberantly and are later refined (Callaway and Katz, 1990); binocular lid suture prevents the refinement of clustered connections (Callaway and Katz, 1991). Does the development of vertical specificity also contrast with the development of horizontal specificity in terms of activity dependence? In the macaque monkey, early laminar specificity clearly develops in the absence of patterned visual activity since it is present before birth (Lund et al., 1977). Laminar specificity of layer $2 / 3$ pyramidal neurons in cat striate cortex also develops normally in lid-sutured cats (observed at P39; E. M. Callaway and L. C. Katz, unpublished observations). The present study demonstrates that the quantitative difference in projection density of layer 4 spiny neurons to deep versus superficial layers does not require patterned activity. However, as noted above (see Results), the single time-point investigations in the cat cannot rule out the possibility of early exuberance that is eliminated before P39. Furthermore, there is almost certainly substantial, nonvisually mediated cortical activity in both prenatal macaques and lid-sutured cats. Future experiments in which cortical activity is blocked directly should therefore be more instructive as to the importance of activity in the development of specific vertical intrinsic connections. Nevertheless, the activity dependence of the development of specific horizontal and vertical connections is distinctly different in that patterned visual activation is necessary for the emergence of horizontal specificity but not for vertical specificity.

Emergence of visual responsiveness and elaboration of complex response properties. The timing with which visual responsiveness and complex neuronal response properties develop in the primary visual cortex of the cat has been investigated in considerable detail (see Frégnac and Imbert, 1984, for review). However, until recently there has been little information about the development of intrinsic cortical circuitry that might contribute to the emergence of neuronal response properties. The work of Albus and Wolf (1984) provides a detailed laminar analysis of the emergence of visual responsiveness and neuronal response properties. Of particular interest with regard to the present study is the timing with which neurons outside of layers 4 and 6 become visually responsive and adultlike orientation specificity emerges.

The layers of cat striate cortex that respond earliest to visual stimuli are the geniculate recipient layers, 4 and 6 (Albus and Wolf, 1984). How does the timing of the development of layer 4 excitatory projections relate to increases in the incidence of visually activated neurons in layers $2 / 3$ and 5 ? We found that weak projections to layer 5 are present at P5-P8 and reach adult extent by PI5, while projections to layer $2 / 3$ first emerge at about P15 and continue to increase in extent after the fourth postnatal week. Consistent with these findings, visually responsive neurons in layer 5 are rare at P6-P9 but much more common than in layer $2 / 3$. By the end of the second postnatal week, however, the incidence of responsive neurons in layer 5 changes very little despite increased projections from layer 4 . Not until the third postnatal week does visual activation of layer 5 neurons increase substantially; this coincides with increases in both the activation of layer $2 / 3$ neurons and projections from layer 4 to layer $2 / 3$. Thus, initial weak activation of layer 5 may be due to direct projections from layer 4 , while subsequent increases 
probably result primarily from the elaboration of projections to layer $2 / 3$ neurons, which already make strong projections to layer 5 before the third postnatal week (Katz, 1991). These results imply that the major pathway for activation of layer 5 neurons in the adult is via excitatory projections from layer $2 / 3$ neurons that are activated by projections from layer 4 . This has been proposed previously based on both anatomical and physiological studies of the strength of projections from layer 4 to supragranular versus infragranular layers (Mitzdorf and Singer, 1978; Gilbert, 1983; Martin, 1984).

Although the increase in visual activation of layer $2 / 3$ coincides with the appearance of projections from layer 4 spiny neurons at the beginning of the third postnatal week, both are still far from adultlike. The incidence of visually responsive neurons observed by Albus and Wolf (1984) in their oldest age group (P20-P24) was still low. At P20-P26 the complexity of projections from layer 4 spiny neurons to layer $2 / 3$ is also immature (about half the P33 value). Thus, a strong correlation exists between the development of excitatory projections to layer $2 / 3$ and increasing visual responsiveness of that layer.

What is the role of intrinsic circuitry in the generation of orientation selectivity? At about 1 week postnatal, many visually responsive neurons have a preferred orientation (Hubel and Wiesel, 1963; Blakemore and Van Sluyters, 1975; Albus and Wolf, 1984; Braastad and Heggelund, 1985). At this time the projections of layer 4 spiny neurons are extremely sparse and visual responsiveness is confined to layers 4 and 6 . Thus, early orientation preferences probably reflect the organization of geniculocortical connectivity (see also Chapman et al., 1991). The degree of orientation selectivity improves rapidly between about P10 and P18 (Blakemore and Van Sluyters, 1975; Albus and Wolf, 1984; Braastad and Heggelund, 1985); the great majority of visually responsive neurons remains confined to layers 4 and 6 (Albus and Wolf, 1984), and projections from layer 4 to layer $2 / 3$ are just beginning to form. The complexity of the intralaminar projections of layer 4 spiny neurons (number of collateral terminations within layer 4 per cell), on the other hand, doubles during this period (Table 1, Fig. $3 B$ ), suggesting that these projections could be particularly important for the construction of highly orientation-selective receptive fields.

Development of clustered horizontal connections. Layer $2 / 3$ pyramidal neurons in adult cat striate cortex receive strong excitatory inputs from layer 4 spiny neurons (Mitzdorf and Singer, 1978; Gilbert, 1983; Martin, 1984) and extend clustered horizontal axon collaterals that specifically interconnect iso-orientation columns (Gilbert and Wiesel, 1989). The development of clustered connections can be considered in two stages: (1) the emergence of crude clusters from an initially unclustered pattern of connections, which occurs even in the absence of patterned visual experience, and (2) the refinement of crude clusters, which involves the rearrangement of horizontal axon collaterals and relies on patterned visual experience to attain the normal adult level of columnar specificity (Callaway and Katz, 1990, 1991). We found that projections from layer 4 spiny neurons to layer $2 / 3$ do not appear until after horizontal connections are already crudely clustered (at P8). The refinement of clustered connections, on the other hand, correlates closely with the elaboration of excitatory projections from layer 4 to layer $2 / 3$.

These observations suggest specific interactions between components of the developing intrinsic cortical circuitry that may be important for assuring the normal adult patterns and specificity of connectivity. Horizontal axon collaterals of layer $2 / 3$ pyramidal neurons can apparently make a crude approximation of their correct adult targets in the absence of either patterned visual cortical activation or layer 4 to layer $2 / 3$ projections. Thus, if activity is important in this stage of cluster development, the relevant activity cues arise from other sources. For example, geniculate afferents can contact pyramidal neurons in layer $2 / 3$ or 5 directly (Davis and Sterling, 1979; Freund et al., 1985 ) or layer 4 spiny neurons could make functional contacts within layer 4 to the basal dendrites of layer 3 pyramidal neurons.

The relationships between cluster refinement and the emergence of connections from layer 4 can be interpreted more easily. As described above, orientation selectivity is improved first within layer 4 , and then at later ages this information is passed on to layer $2 / 3$, presumably by the axons of layer 4 spiny neurons, which are elaborated at the same time. Since the refinement of clusters is also temporally correlated with the emergence of visual responsiveness in layer $2 / 3$, the role of the layer 4 to $2 / 3$ projection in cluster refinement could be to provide orientation information to layer $2 / 3$ pyramidal neurons. They could then use this information to select between correct and incorrect orientation columns during the rearrangement of their axon collaterals.

\section{References}

Albus K, Wolf W (1984) Early post-natal development of neuronal function in the kitten's striate cortex: a laminar analysis. J Physiol (Lond) 348:153-185.

Blakemore C, Van Sluyters RC (1975) Innate and environmental factors in the development of the kitten's visual cortex. J Physiol (Lond) 248:663-716.

Braastad BO, Heggelund P (1985) Development of spatial receptivefield organization and orientation selectivity in kitten striate cortex. J Neurophysiol 53:1158-1178.

Burkhalter A, Bernardo KL, Charles V (1990) Postnatal development of intracortical connections in human visual cortex. Soc Neurosci Abstr 16:1129.

Callaway EM, Katz LC (1990) Emergence and refinement of clustered horizontal connections in cat striate cortex. J Neurosci 10:1134-1153.

Callaway EM, Katz LC (1991) Effects of binocular deprivation on the development of clustered horizontal connections in cat striate cortex. Proc Natl Acad Sci USA 88:745-749.

Chapman B, Zahs KR, Stryker MP (1991) Relation of cortical cell orientation selectivity to alignment of receptive fields of the geniculocortical afferents that arborize within a single orientation column in ferret visual cortex. J Neurosci 11:1347-1358.

Chun JJM, Shatz CJ (1988) Redistribution of synaptic vesicle antigen is correlated with the disappearance of a transient synaptic zone in the developing cerebral cortex. Neuron 1:297-310.

Davis TL, Sterling P (1979) Microcircuitry of cat visual cortex: classification of neurons in layer IV of area 17, and identification of the patterns of lateral geniculate input. J Comp Neurol 188:599-628.

Einstein G, Davis TL, Sterling P (1987) Pattern of lateral geniculate synapses on neuron somata in layer IV of the cat siriate cortex. I Comp Neurol 260:76-86.

Frégnac Y, Imbert M (1984) Development of neuronal selectivity in primary visual cortex of cat. Physiol Rev 64:325-434.

Freund TF, Martin KAC, Somogyi P, Whitteridge D (1985) Innervation of cat visual areas 17 and 18 by physiologically identified $\mathrm{X}$ - and $\mathrm{Y}$-type thalamic afferents. II. Identification of postsynaptic targets by GABA immunohistochemistry and Golgi impregnation. J Comp Neurol 242:275-291.

Friauf E, McConnell SK, Shatz CJ (1990) Functional synaptic circuits in the subplate during fetal and early postnatal development of cat visual cortex. J Neurosci 10:2601-2613.

Gilbert CD (1977) Laminar differences in receptive field properties of cells in cat primary visual cortex. J Physiol (Lond) 268:391-421.

Gilbert CD (1983) Microcircuitry of the visual cortex. Annu Rev Neurosci 6:217-247.

Gilbert CD, Wiesel TN (1979) Morphology and intracortical projec- 
tions of functionally characterized neurones in the cat visual cortex Nature 280:120-125.

Gilbert CD, Wiesel TN (1983) Clustered intrinsic connections in cat visual cortex. J Neurosci 3:1116-1133.

Gilbert CD, Wiesel TN (1989) Columnar specificity of intrinsic horizontal and cortico-cortical connections in cat visual cortex. J Neurosci 9:2432-2442.

Hubel DH, Wiesel TN (1962) Receptive fields, binocular interaction and functional architecture in the cat's visual cortex. J Physiol (Lond) 160:106-154.

Hubel DH, Wiesel TN (1963) Receptive fields of cells in striate cortex of very young, visually inexperienced kittens. J Neurophysiol 26:994 1002

Huttenlocher PR (1967) Development of cortical neuronal activity in the neonatal cat. Exp Neurol 17:247-262.

Katz LC (1987) Local circuitry of identified projection neurons in cat visual cortex brain slices. J Neurosci 7:1223-1249.

Katz LC (1991) Specificity in the development of vertical connections in cat striate cortex. Eur J Neurosci 3:1-9.

Katz LC, Callaway EM (1991) Emergence and refinement of local circuits in cat striate cortex. In: Development of the visual system (Lam DM, Shatz CJ, eds), pp 197-215. Cambridge, MA: MIT Press.

Katz LC, Callaway EM (1992) Development of local circuits in mammalian visual cortex. Annu Rev Neurosci 15:31-56.

Kelly J, Van Essen D (1973) Correlation of cell shape and function in the visual cortex of the cat. Nature 241:403-405.

LeVay S, Gilbert CD (1976) Laminar patterns of geniculocortical projection in the cat. Brain Res 113:1-19.

Lund JS, Boothe RG, Lund RD (1977) Development of neurons in the visual cortex of the monkey (Macaca nemestrina): a Golgi study from fetal day 127 to postnatal maturity. J Comp Neurol 176:149188.
Lund JS, Henry GH, MacQueen CL, Harvey AR (1979) Anatomical organization of the primary visual cortex (area 17) of the cat. A comparison with area 17 of the macaque monkey. J Comp Neurol 184:599-618.

Luskin MB, Shatz CJ (1985) Neurogenesis of the cat's primary visual cortex. J Comp Neurol 242:611-631.

Martin KAC (1984) Neuronal circuits in cat striate cortex. In: Cerebral cortex, Vol 2 (Jones EG, Peters A, eds), pp 241-284. New York: Plenum

Martin KAC, Whitteridge D (1984) Form, function and intracortical projections of spiny neurons in the striate cortex of the cat. J Physiol (Lond) 353:463-504.

Mitzdorf U, Singer W (1978) Prominent excitatory pathways in the cat visual cortex (A 17 and A 18): a current source density analysis of electrically evoked potentials. Exp Brain Res 33:371-394.

O'Leary JL (1941) Struclure of the area striata of the cat. J Comp Neurol 75:131-161.

Otsuka R, Hassler H (1962) Uber Aufbau und Gliederung der corticalen Sehsphare bei der Katze. Arch Psychiatr Nevenkr 203:21 2-234.

Ramon y Cajal SR (1911) Histologie du systeme nerveux de l'homme et des vertebres. Reprint. Madrid: Consejo Superior de Investigaciones Cientificas, 1972.

Shatz CJ, Luskin MB (1986) The relationship between the geniculocortical afferents and their cortical target cells during development of the cat's primary visual cortex. J Neurosci 6:3655-3668.

Shatz CJ, Chun JJM, Luskin MB (1988) The role of the subplate in the development of the mammalian telencephalon. In: Cerebral cortex: development and maturation of cerebral cortex (Peters A, Jones EG, eds), vol 7, pp 35-58. New York: Plenum.

Wiesel TN, Hubel DH (1965) Comparison of the effects of unilateral and bilateral eye closure on cortical unit responses in kittens. J Neurophysiol 28:1029-1040. 